\title{
Critical Variables of Solder Paste Stencil Printing for Micro-BGA and Fine-Pitch QFP
}

\author{
Jianbiao Pan, Member, IEEE, Gregory L. Tonkay, Robert H. Storer, Ronald M. Sallade, and David J. Leandri
}

\begin{abstract}
Stencil printing continues to be the dominant method of solder deposition in high-volume surface-mount assembly. Control of the amount of solder paste deposited is critical in the case of fine-pitch and ultrafine-pitch surface-mount assembly. The process is still not well understood as indicated by the fact that industry reports 52-71\% surface-mount technology (SMT) defects are related to the solder paste stencil printing process.

The purpose of this paper is to identify the critical variables that influence the volume, area, and height of solder paste deposited. An experiment was conducted to investigate the effects of relevant process parameters on the amount of solder paste deposited for ball grid arrays (BGAs) and quad flat packages (QFPs) of five different pitches ranging from $0.76 \mathrm{~mm}(30 \mathrm{mil})$ to $0.3 \mathrm{~mm}(12 \mathrm{mil})$. The effects of aperture size, aperture shape, board finish, stencil thickness, solder type, and print speed were examined. The deposited solder paste was measured by an inline fully automatic laser-based three-dimensional (3-D) triangulation solder paste inspection system.

Analysis of variance (ANOVA) shows that aperture size and stencil thickness are the two most critical variables. A linear relationship between transfer ratio (defined as the ratio of the deposited paste volume to the stencil aperture volume) and area ratio (defined as the ratio of the area of the aperture opening to the area of the aperture wall) is proposed. The analysis indicates that the selection of a proper stencil thickness is the key to controlling the amount of solder paste deposited, and that the selection of maximum stencil thickness should be based on the area ratio. The experimental results are shown to be consistent with a theoretical model, which will also be described in this paper.
\end{abstract}

Index Terms-Analysis of variance (ANOVA), area ratio, design of experiment, solder paste, stencil printing, transfer ratio.

\section{INTRODUCTION}

$\mathbf{T}$ HE NEED for higher pin count, higher performance, smaller size, and lighter weight has driven the development of advanced packages such as quad flat package (QFP), ball grid array (BGA), chip scale package (CSP), and flip chip. These high-density packages have had a tremendous impact on board-level assembly. One of the main challenges continues to be the solder paste deposition process and, specifically, controlling the amount of solder paste deposited.

Stencil printing is one of the most cost-effective processes for solder paste deposition and it has been widely used in traditional

Manuscript received September 23, 2003; revised December 19, 2003 and February 23, 2004.

J. Pan is with the Department of Industrial and Manufacturing Engineering, California Polytechnic State University, San Luis Obispo, CA 93410 USA.

G. L. Tonkay and R. H. Storer are with the Department of Industrial and Systems Engineering, Lehigh University, Bethlehem, PA 18015 USA.

R. M. Sallade is with Cygnus Inc., Redwood City, CA 94063 USA.

D. J. Leandri is with American Technical Ceramics, Jacksonville, FL 32216 USA.

Digital Object Identifier 10.1109/TEPM.2004.837965

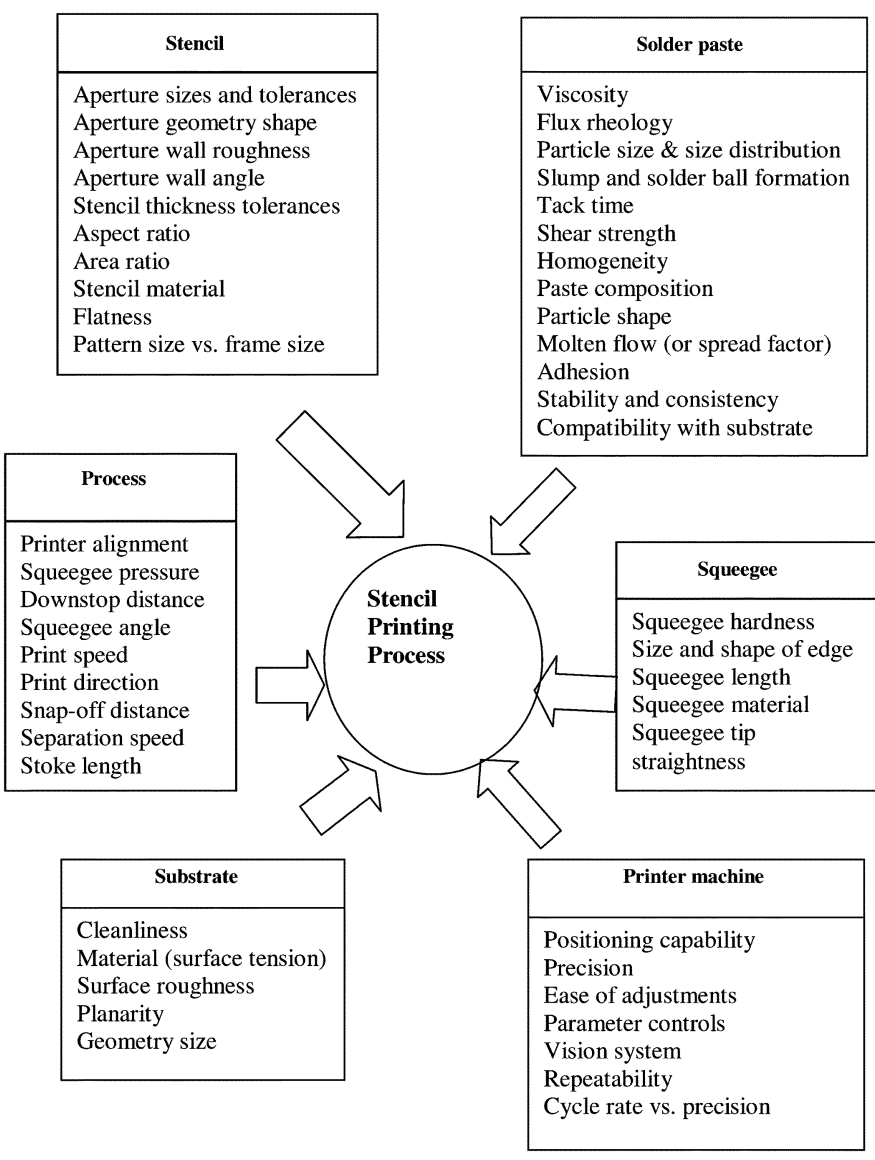

Fig. 1. Factors that influence the stencil printing process.

surface mount assembly. If the process can apply solder balls for BGA, CSP and flip chip assembly, it will accelerate the development and utilization of these advanced packages. However, the solder paste stencil printing process is still not completely understood, as indicated by the fact that industry reports $52-71 \%$ of fine-pitch SMT defects are related to the solder paste stencil printing process [1].

The stencil printing process is described as follows: When the squeegee is moved along the stencil surface, it forces the solder paste to roll in front of the squeegee and generate a high pressure. The high pressure injects the solder paste into the stencil aperture, which covers the desired areas of the pad of the printed circuit board (PCB). The stencil is lifted off after the print stroke is finished and the solder paste is left on the pad of the PCB [2].

There are many variables that influence the quality of the stencil printing process, which is measured by the amount and position of solder paste deposited. Fig. 1 gives a list of important process variables. Pan [10] reviewed the work on investigating 
the effects of the process variables. Since there are more than 45 variables, to identify the critical variables is necessary.

An analytical model of the aperture filling process in solder paste stencil printing was developed [2]. In this model, aperture opening size, stencil thickness, and squeegee attack angle are concluded to be three critical variables. The deposited solder volume is independent of the stencil thickness. If the squeegee attack angle is fixed and the seal condition between the squeegee and the stencil remains the same, the relationship between transfer ratio and area ratio is

$$
\begin{aligned}
& \mathrm{TR}=C * \mathrm{AAR} \quad \mathrm{AAR}<\text { a critical value } \\
& \mathrm{TR}=1 \quad \mathrm{AAR}>\text { a critical value }
\end{aligned}
$$

where TR is the transfer ratio, which is defined as the deposition volume divided by the aperture volume; $C$ is a constant; AAR is the area ratio, which is defined as the ratio of the area of aperture opening to the area of the sidewall of the aperture.

For a circular (BGA) aperture: $\mathrm{ARR}=R /(2 H)$

For a rectangle $(\mathrm{QFP})$ aperture: $\mathrm{ARR}=\mathrm{LW} /[2(L+W) H]$

where $R$ is the radius of the circular aperture, $H$ is the stencil thickness, $L$ is the length of the rectangular aperture, and $W$ is the width of the rectangular aperture.

The critical AAR value is where deposited solder paste volume equals the aperture volume and no excess paste is scooped. The critical value and constant $C$ can be obtained through experimentation. Note that the critical AAR value and constant $C$ depend on the squeegee attack angle and the seal condition between the squeegee and the stencil. The model shows that thicker stencils do not necessarily mean higher solder prints and the selection of maximum stencil thickness should be based on the area ratio.

\section{EXPERIMENT DESIGN}

The goal of this experiment is to determine which are the critical variables that control the amount of solder paste deposited, to validate the model, and to determine the critical AAR value. Based on the model, the previous studies [1]-[10], and discussions with the engineers at Visteon, six variables were selected for this study. They are stencil thickness, aperture size, aperture shape, board finish, solder paste type, and print speed. The response variable is the volume, area, and height of solder paste deposited, which was measured by an inline fully automatic laser-based three-dimensional (3-D) solder paste inspection system. Table I summaries the variables and their levels for the experiment. Table II shows the aperture size of the stencils. Table III compares the solder paste characteristics of Type 3 and Type 4.

The stencil used for the research was laser-cut from stainless steel. Two stencil thicknesses were selected. One is $0.1 \mathrm{~mm}(4$ mil) and the other was $0.15 \mathrm{~mm}$ (6 mil). Both of the stencils had the same pattern, which included three aperture groups.

Group 1) Regular rectangular (QFP) apertures with widths of $0.38 \mathrm{~mm}$ (15 mil), $0.32 \mathrm{~mm}$ (12 mil), 0.25 $\mathrm{mm}(10 \mathrm{mil}), 0.2 \mathrm{~mm}(8 \mathrm{mil})$, and $0.15 \mathrm{~mm}(6$ mil). Each width had 102 pads in the "parallel to
TABLE I

INPUT VARIABLES AND THEIR LEVELS

\begin{tabular}{l|l|l}
\hline Stencil thickness & $0.1 \mathrm{~mm}(4 \mathrm{mil})$ & $0.15 \mathrm{~mm}(6 \mathrm{mil})$ \\
\hline Solder paste type & Type 3 & Type 4 \\
\hline Board finish & Immersion $\mathrm{Ag}$ & HASL* \\
\hline Print speed & $2 \mathrm{in} / \mathrm{sec}$ & $8 \mathrm{in} / \mathrm{sec}$ \\
\hline Aperture size & See Table 2 & \\
\hline Aperture shape & See Figure 2 & \\
\hline HASL $=$ Hot Air Solder Leveling.
\end{tabular}

TABLE II

APERTURE SizES OF A STENCIL (UNIT: mil $=0.0254 \mathrm{~mm}$ )

\begin{tabular}{l|l|l|l|l|l}
\hline Pitch (mil) & 30 & 25 & 20 & 16 & 12 \\
\hline QFP aperture width & 15 & 12 & 10 & 8 & 6 \\
\hline QFP aperture length & 80 & 70 & 60 & 50 & 40 \\
\hline BGA aperture diameter & 15 & 12 & 10 & 8 & 6 \\
\hline
\end{tabular}

TABLE III

SOLDER PASTE SPECIFICATION

\begin{tabular}{l|l|l}
\hline & Type 3 & Type 4 \\
\hline Dimension & $90-3-\mathrm{M} 10$ & $90-4-\mathrm{M} 10$ \\
\hline Viscosity @5rpm & 1570 poise & 1620 poise \\
\hline Viscosity @30rpm & 430 poise & 480 poise \\
\hline F.O.G.* & $40 / 32 \mu \mathrm{m}$ & $27 / 24 \mu \mathrm{m}$ \\
\hline Alloy & Sn62/Pb36/Ag2 \\
\hline Metal content & $90 \%$ & \\
\hline Flux type & No-clean LR 735 \\
* F.O.G. (Fineness of Grind) is a simple test to check for the largest particle/agglomerate \\
size in a paste.
\end{tabular}

squeegee travel" orientation and 102 pads in the "perpendicular to squeegee travel" orientation. A total of 1020 pads were evaluated.

Group 2) Slant rectangular (QFP) apertures with widths of $0.38 \mathrm{~mm}$ (15 mil), $0.32 \mathrm{~mm}$ (12 mil), $0.25 \mathrm{~mm}$ (10 mil), $0.2 \mathrm{~mm}$ (8 mil), and $0.15 \mathrm{~mm}(6 \mathrm{mil})$. Each width had 30 pads in the " $45^{\circ}$ to squeegee travel" orientation and 30 pads in the " $135^{\circ}$ to squeegee travel" orientation. A total of 300 pads were evaluated. Note that the distance of aperture-to-aperture is designed much larger than the pitch to make measurement feasible.

Group 3) Circular (BGA) apertures with the diameters of $0.38 \mathrm{~mm}$ (15 mil), $0.32 \mathrm{~mm}$ (12 mil), $0.25 \mathrm{~mm}$ (10 mil), $0.2 \mathrm{~mm}(8 \mathrm{mil})$, and $0.15 \mathrm{~mm}(6 \mathrm{mil})$. Each diameter had 216 pads. A total of 1080 pads were evaluated.

The test pattern was designed as a $3 \times 3$ Latin Square so the variability due to the pad positions relative to the squeegee and squeegee travel direction were eliminated. The test pattern is shown in Fig. 2. It should be noted that the information about aperture size and shape in this design is confounded because they are all in a block. The other four factors, stencil thickness, board finish, solder type, and print speed were designed as a factorial design. Due to the time limit of the use of the printing machine in a production line, only one replication was selected. So, a total of 16 boards (two-level four factors factorial design) were printed.

In order to generate comparative data on specified process variables, the remaining process variables were determined 


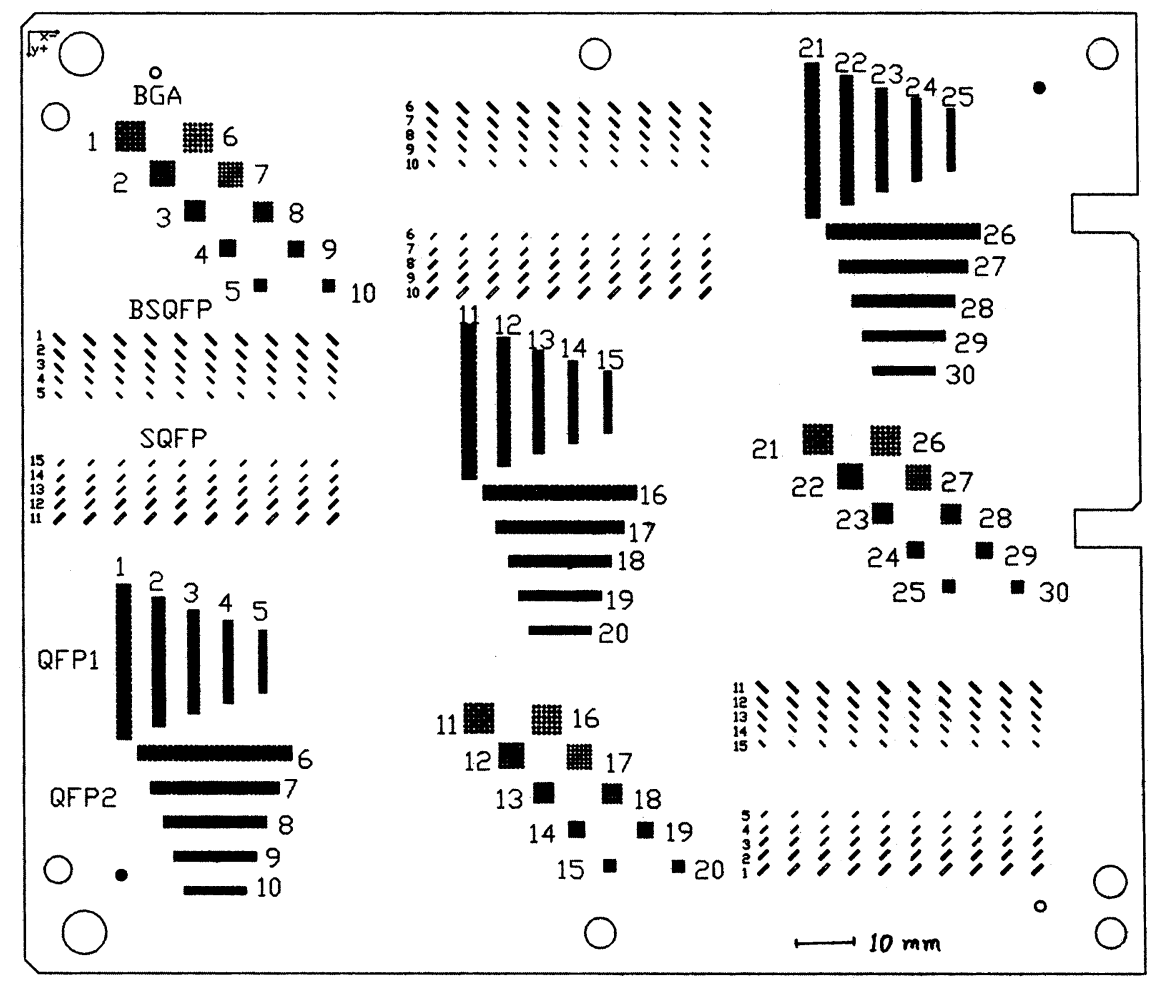

Fig. 2. Test pattern of stencils and FR-4 boards.

TABLE IV

PROCESS VARIABLES

\begin{tabular}{l|l}
\hline Printer & MPM AP HiE \\
\hline Squeegee & 8 inch metal squeegee blade with 45 degree \\
\hline Squeegee pressure & $8 \mathrm{bb}$ \\
\hline Down-stop distance & 0.0835 inch \\
\hline Snap-off distance & On-contact \\
\hline Separation speed & Level $6($ about $0.6-0.9 \mathrm{~mm} / \mathrm{s})$ \\
\hline Stencil mesh tension & $28 \mathrm{~N} / \mathrm{cm}$ \\
\hline
\end{tabular}

based on the engineer's knowledge and experience and limited to the values shown in Table IV.

In order to keep solder paste properties the same for each run, the paste was kneaded three times before printing. The reason is that the viscosity of solder paste may change after it was kneaded a different number of times. To get the steady state results, each run printed three times and only the third print was measured because the results of the first two may be unstable. The third board of each run was measured right after it was printed since a long wait time between print and measurement could cause the solvent of paste to evaporate and result in a lower amount when measured.

A fully automatic solder paste inspection system is currently used for inspection of $0.635 \mathrm{~mm}$ (25 mil) QFP components of automobile electronics products. An experiment was conducted to investigate whether the system can be used successfully for measuring $0.4 \mathrm{~mm}$ and $0.3 \mathrm{~mm}$ pitch QFPs and BGAs [3]. The results indicate that the system is capable of measuring down to $0.3 \mathrm{~mm}$ (12 mil) pitch QFPs and $0.5 \mathrm{~mm}$ (20 mil) pitch BGAs, but fails for $0.4 \mathrm{~mm}$ (16 mil) and $0.3 \mathrm{~mm}$ (12 mil) pitch BGAs in this project due to too small solder deposits. Therefore, the data of $0.4 \mathrm{~mm}$ and $0.3 \mathrm{~mm}$ pitch BGAs was removed in the analysis which will be described in Section III.
TABLE V

ANOVA FOR QFP SOLDER DEPOSITED VOLUME

\begin{tabular}{l|l|l|l|l}
\hline Source & Sum of Squares & Df & Mean Square & F-Ratio \\
\hline Main effect & & & & \\
\hline A:Pitch & 4.77883 & 4 & 1.19471 & 40964.5 \\
\hline B:Stencil Thickness & 0.542481 & 1 & 0.542481 & 18600.7 \\
\hline C:Aperture Shape & 0.0174194 & 3 & 0.00580648 & 199.09 \\
\hline D:Board Finish & 0.0057145 & 1 & 0.00571457 & 195.94 \\
\hline E:Solder Type & 0.0001592 & 1 & 0.000159239 & 5.46 \\
\hline F:Print Speed & 0.0056206 & 1 & 0.00562065 & 192.72 \\
\hline Interactions & & & & \\
\hline AB & 0.364078 & 4 & 0.0910194 & 3120.90 \\
\hline AC & 0.0098917 & 12 & 0.000824316 & 28.26 \\
\hline AD & 0.0048905 & 4 & 0.00122264 & 41.92 \\
\hline AE & 0.0003570 & 4 & 0.000089251 & 3.06 \\
\hline AF & 0.0009143 & 4 & 0.000228578 & 7.84 \\
\hline BC & 0.0267863 & 3 & 0.00892875 & 306.15 \\
\hline BD & 0.0000281 & 1 & 0.000028188 & 0.97 \\
\hline BE & 0.0128406 & 1 & 0.0128406 & 440.28 \\
\hline BF & 0.0140634 & 1 & 0.0140634 & 482.21 \\
\hline CD & 0.0024322 & 3 & 0.000810743 & 27.80 \\
\hline CE & 0.0016842 & 3 & 0.000561407 & 19.25 \\
\hline DF & 0.0037196 & 3 & 0.00123988 & 42.51 \\
\hline DE & 0.0080697 & 1 & 0.00806978 & 276.70 \\
\hline EF & 0.0017877 & 1 & 0.00178774 & 61.30 \\
\hline Residual & 0.0223297 & 1 & 0.0223297 & 765.65 \\
\hline Total (Corrected) & 0.194294 & 6662 & 0.000029164 & \\
\hline & 6.01839 & 6719 & & \\
\hline & & & & \\
\hline & & 1 & & \\
\hline
\end{tabular}

\section{ANALYSIS OF THE DATA}

\section{A. Effects of Aperture Size and Stencil Thickness}

The data were analyzed using analysis of variance (ANOVA). The ANOVA table for the volume of solder paste deposited for QFP apertures is shown in Table V. It shows that aperture size (pitch) and stencil thickness have statistically significant effects on the volume of solder deposited. It is intuitive that a bigger aperture will result in more volume than a smaller one. One 


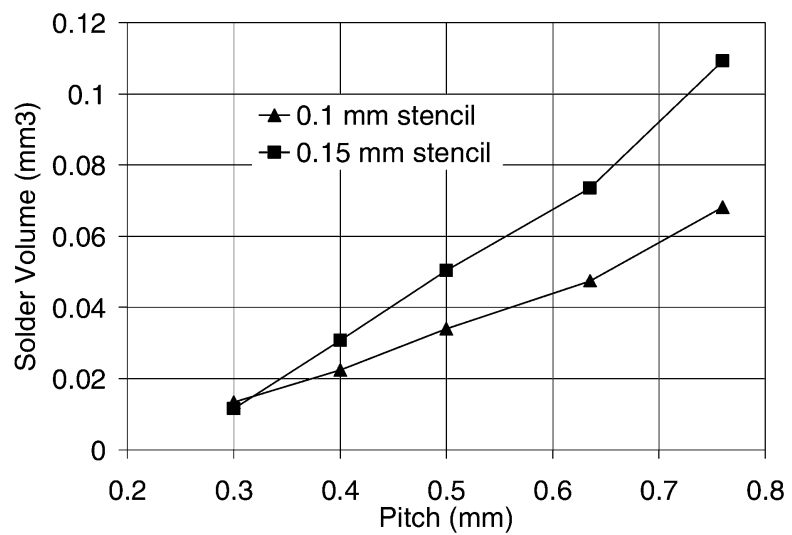

Fig. 3. Interaction plot of QFP aperture size and stencil thickness.

TABLE VI

ANOVA FOR BGA SOLDER VOLUME

\begin{tabular}{l|l|l|l|l}
\hline Source & Sum of Squares & Df & Mean Square & F-Ratio \\
\hline Main Effects & & & & \\
\hline A:Pitch & 0.0965794 & 2 & 0.0482897 & 28506.03 \\
\hline B:Stencil Thickness & 0.000286738 & 1 & 0.000286738 & 169.27 \\
\hline C:Board Finish & 0.000812605 & 1 & 0.000812605 & 479.69 \\
\hline D:Print Speed & 0.0000336707 & 1 & 0.0000336707 & 19.88 \\
\hline E: Solder Type & 0.0000108915 & 1 & 0.0000108915 & 6.43 \\
\hline Interactions & & & & \\
\hline AB & 0.00990379 & 2 & 0.0049519 & 2923.17 \\
\hline AC & 0.00016399 & 2 & 0.0000819951 & 48.40 \\
\hline AD & 0.0000157014 & 2 & 0.0000078506 & 4.63 \\
\hline AE & 0.000100836 & 2 & 0.000050418 & 29.76 \\
\hline BC & $9.89627 \mathrm{E}-9$ & 1 & $9.89627 \mathrm{E}-9$ & 0.01 \\
\hline BD & $9.85175 \mathrm{E}-7$ & 1 & $9.85175 \mathrm{E}-7$ & 0.58 \\
\hline BE & 0.000355628 & 1 & 0.000355628 & 209.93 \\
\hline CD & 0.000175921 & 1 & 0.000175921 & 103.85 \\
\hline CE & 0.000120655 & 1 & 0.000120655 & 71.22 \\
\hline DE & 0.000428299 & 1 & 0.000428299 & 252.83 \\
\hline Residual & 0.00972196 & 5739 & 0.0000016940 & \\
\hline Total (Corrected) & 0.118711 & 5759 & & \\
\hline & & & &
\end{tabular}

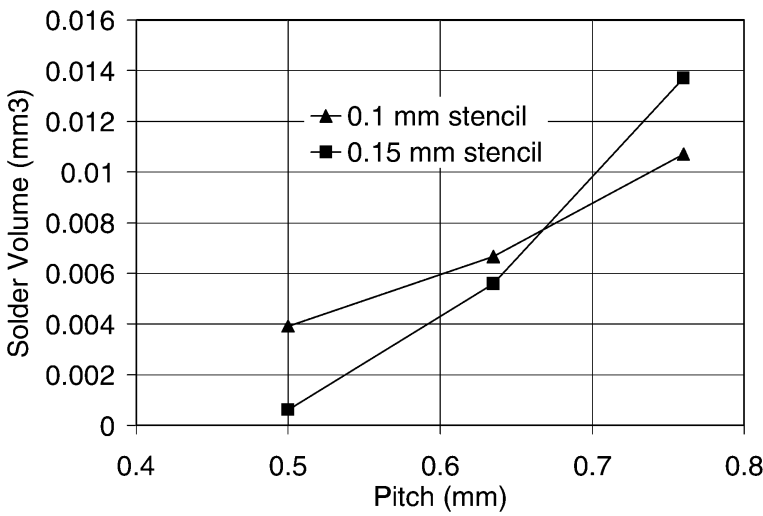

Fig. 4. Interaction plot of BGA aperture size and stencil thickness.

may think that a thicker stencil will deposit more volume than a thinner one too. However, this is not always true. The interaction plot of QFP aperture size and stencil thickness in Fig. 3 shows that the $0.1 \mathrm{~mm}(4 \mathrm{mil})$ stencil deposited more volume than the $0.15 \mathrm{~mm}$ (6 mil) stencil at the $0.3 \mathrm{~mm}$ pitch level. The ANOVA table for the volume of solder paste deposited for BGA apertures is shown in Table VI. The interaction plot of BGA aperture size and stencil thickness in Fig. 4 shows that the $0.1 \mathrm{~mm}$ stencil deposited more volume than the $0.15 \mathrm{~mm}$ stencil at the $0.5 \mathrm{~mm}$
TABLE VII

AREA RATIO (AAR) AND APERTURE VOLUME

\begin{tabular}{|c|c|c|c|c|c|c|}
\hline \multirow[t]{2}{*}{$\begin{array}{l}\text { Aperture } \\
\text { shape }\end{array}$} & \begin{tabular}{|l|} 
Pitch \\
(mils)
\end{tabular} & \multicolumn{2}{|c|}{$\begin{array}{l}\text { Aperture } \\
\text { size (mils) }\end{array}$} & $\begin{array}{l}\text { Stencil thickness } \\
\mathrm{H} \text { (mils) }\end{array}$ & $\begin{array}{l}\text { AAR (BGA: R/2H; } \\
\text { QFP: } \\
\text { LW/[2(L+W)H]) }\end{array}$ & \begin{tabular}{|l|} 
Aperture \\
Volume \\
$\left(10^{-3} \mathrm{~mm}^{-3}\right.$
\end{tabular} \\
\hline & & \multicolumn{2}{|c|}{ Diameter } & & & \\
\hline \multirow{11}{*}{ BGA } & \multirow[t]{2}{*}{12} & \multirow{2}{*}{\multicolumn{2}{|c|}{6}} & 4 & 0.375 & 1.853 \\
\hline & & & & 6 & 0.25 & 2.780 \\
\hline & \multirow[t]{2}{*}{16} & \multirow{2}{*}{\multicolumn{2}{|c|}{8}} & 4 & 0.5 & 3.295 \\
\hline & & & & 6 & 0.33 & 4.942 \\
\hline & \multirow[t]{2}{*}{20} & \multirow{2}{*}{\multicolumn{2}{|c|}{10}} & 4 & 0.625 & 5.148 \\
\hline & & & & 6 & 0.42 & 7.722 \\
\hline & \multirow[t]{2}{*}{25} & \multirow{2}{*}{\multicolumn{2}{|c|}{12}} & 4 & 0.75 & 7.413 \\
\hline & & & & 6 & 0.5 & 11.12 \\
\hline & \multirow[t]{3}{*}{30} & \multirow{2}{*}{\multicolumn{2}{|c|}{15}} & 4 & 0.94 & 11.58 \\
\hline & & & & 6 & 0.625 & 17.37 \\
\hline & & W & L & & & \\
\hline \multirow{10}{*}{ QFP } & \multirow[t]{2}{*}{12} & \multirow[t]{2}{*}{6} & \multirow[t]{2}{*}{40} & 4 & 0.65 & 15.732 \\
\hline & & & & 6 & 0.43 & 23.597 \\
\hline & \multirow{2}{*}{16} & \multirow[t]{2}{*}{8} & \multirow[t]{2}{*}{50} & 4 & 0.86 & 26.219 \\
\hline & & & & 6 & 0.57 & 39.329 \\
\hline & \multirow[t]{2}{*}{20} & \multirow[t]{2}{*}{10} & \multirow[t]{2}{*}{60} & 4 & 1.07 & 39.329 \\
\hline & & & & 6 & 0.71 & 58.993 \\
\hline & \multirow[t]{2}{*}{25} & \multirow[t]{2}{*}{12} & \multirow[t]{2}{*}{70} & 4 & 1.28 & 55.061 \\
\hline & & & & 6 & 0.85 & \begin{tabular}{|l|}
82.591 \\
\end{tabular} \\
\hline & \multirow[t]{2}{*}{30} & \multirow[t]{2}{*}{15} & \multirow[t]{2}{*}{80} & 4 & 1.58 & 78.658 \\
\hline & & & & 6 & 1.05 & 117.987 \\
\hline
\end{tabular}

TABLE VIII

ANOVA FOR QFP SOLDER TRANSFER RATIO

\begin{tabular}{l|l|l|l|l}
\hline Source & Sum of Squares & Df & Mean Square & F-Ratio \\
\hline Main Effects & & & & \\
\hline A:Pitch & 45.1981 & 4 & 11.2995 & 760.07 \\
\hline B:Stencil Thickness & 8.72832 & 1 & 8.72832 & 587.11 \\
\hline C:Aperture Shape & 3.8069 & 3 & 1.26897 & 85.36 \\
\hline D:Board Finish & 1.12135 & 1 & 1.12135 & 75.43 \\
\hline E:Solder Type & 0.163262 & 1 & 0.163262 & 10.98 \\
\hline F:Print Speed & 4.11505 & 1 & 4.11505 & 276.80 \\
\hline Interactions & & & & \\
\hline AB & 38.2819 & 4 & 9.57047 & 643.76 \\
\hline AC & 2.05473 & 12 & 0.171228 & 11.52 \\
\hline AD & 1.31444 & 4 & 0.328611 & 22.10 \\
\hline AE & 0.169955 & 4 & 0.042488 & 2.86 \\
\hline AF & 0.0960456 & 4 & 0.024011 & 1.62 \\
\hline BC & 10.6912 & 3 & 3.56375 & 239.72 \\
\hline BD & 0.34692 & 1 & 0.34692 & 23.34 \\
\hline BE & 5.70317 & 1 & 5.70317 & 383.63 \\
\hline BF & 6.96443 & 1 & 6.96443 & 468.46 \\
\hline CD & 2.79318 & 3 & 0.931059 & 62.63 \\
\hline CE & 1.16527 & 3 & 0.388423 & 26.13 \\
\hline CF & 1.74029 & 3 & 0.580097 & 39.02 \\
\hline DE & 4.14786 & 1 & 4.14786 & 279.01 \\
\hline DF & 2.03097 & 1 & 2.03097 & 136.61 \\
\hline EF & 9.25192 & 1 & 9.25192 & 622.33 \\
\hline Residual & 99.0406 & 6662 & 0.014866 & \\
\hline Total (Corrected) & 248.926 & 6719 & & \\
\hline & & & &
\end{tabular}

pitch and $0.635 \mathrm{~mm}$ pitch level. Similar experimental results were reported by Fujiuchi and Toriyama [8]. They found that the bump volume with a stencil thickness of $60 \mu \mathrm{m}$ is larger than that of a stencil thickness of $80 \mu \mathrm{m}$.

Another analysis was performed using transfer ratio as the response variable. The calculation of area ratio and aperture volume is shown in Table VII. The ANOVA table for the transfer ratio of QFP apertures is shown in Table VIII, and that of BGA apertures in Table IX. The results indicate that pitch (aperture size) and stencil thickness are still the critical variables since they have larger F-ratios. The interaction plot of QFP shown in Fig. 5 illustrates that the transfer ratio of the $0.15 \mathrm{~mm}$ stencil increases as the pitch increases, while the transfer ratio of the 0.1 
TABLE IX

ANOVA FOR BGA SOLDER TRANSFER RATIO

\begin{tabular}{|c|c|c|c|c|}
\hline Source & Sum of Squares & Df & Mean Square & F-Ratio \\
\hline \multicolumn{5}{|l|}{ Main Effects } \\
\hline A:Pitch & 217.495 & 2 & 108.748 & 5514.1 \\
\hline B:Stencil Thickness & 259.224 & 1 & 259.224 & 13144. \\
\hline C:Board Finish & 8.79144 & 1 & 8.79144 & 445.78 \\
\hline D:Print Speed & 0.294222 & 1 & 0.294222 & 14.92 \\
\hline E: Solder Type & 0.0078316 & 1 & 0.00783164 & 0.40 \\
\hline \multicolumn{5}{|l|}{ Interactions } \\
\hline $\mathrm{AB}$ & 77.5489 & 2 & 38.7744 & 1966.0 \\
\hline $\mathrm{AC}$ & 1.00898 & 2 & 0.504492 & 25.58 \\
\hline $\mathrm{AD}$ & 0.158414 & 2 & 0.0792071 & 4.02 \\
\hline $\mathrm{AE}$ & 0.791194 & 2 & 0.395597 & 20.06 \\
\hline $\mathrm{BC}$ & 0.174292 & 1 & 0.174292 & 8.84 \\
\hline $\mathrm{BD}$ & 0.0019776 & 1 & 0.00197768 & 0.10 \\
\hline $\mathrm{BE}$ & 2.55086 & 1 & 2.55086 & 129.34 \\
\hline $\mathrm{CD}$ & 1.73309 & 1 & 1.73309 & 87.88 \\
\hline $\mathrm{CE}$ & 2.09363 & 1 & 2.09363 & 106.16 \\
\hline $\mathrm{DE}$ & 6.17225 & 1 & 6.17225 & 312.97 \\
\hline Residual & 113.182 & 5739 & 0.0197216 & \\
\hline Total (Corrected) & 691.229 & 5759 & & \\
\hline
\end{tabular}

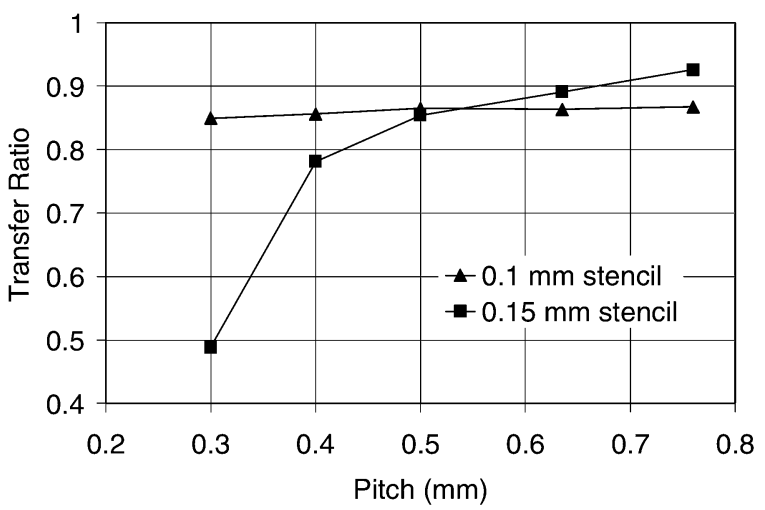

Fig. 5. Transfer ratio versus Pitch for QFP apertures.

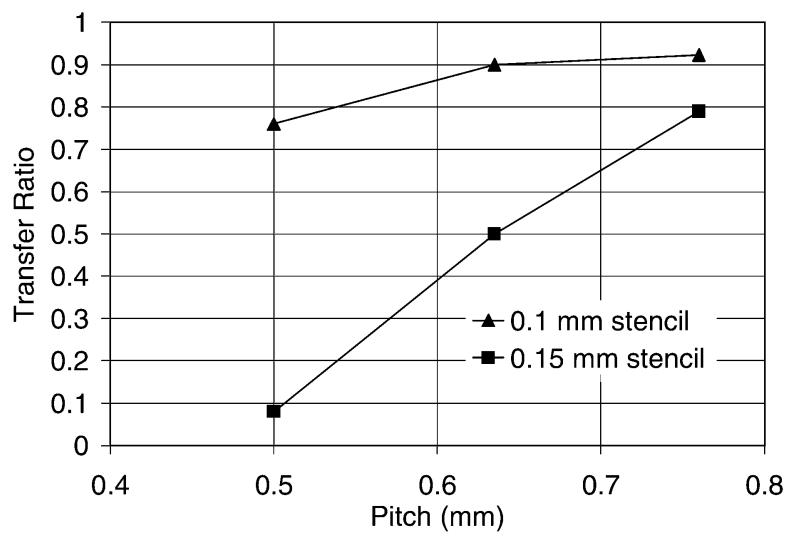

Fig. 6. Transfer ratio versus Pitch for BGA apertures.

$\mathrm{mm}$ stencil remains constant as the pitch increases. The interaction of BGA in Fig. 6 illustrates that the transfer ratio of the 0.15 $\mathrm{mm}$ stencil decreases rapidly as the pitch decreases, while that of the $0.1 \mathrm{~mm}$ stencil decreases slowly as the pitch goes down.

The relationship between transfer ratio and area ratio is shown in Fig. 7. When AAR is larger than 0.6, the transfer ratio is a constant at about 0.9. When AAR is less than 0.6, the transfer ratio is proportional to the area aspect ratio. The difference between the model and experimental results can be explained by
Transfer Ratio vs. Area Ratio

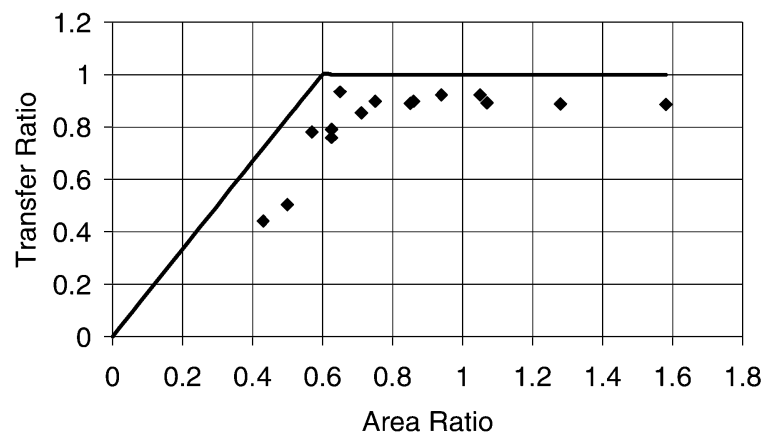

Fig. 7. Comparison of the model and experimental results (points: the overall average of experimental data that have the same area ratio; line: model).

two reasons. The first is that part of the paste is deposited outside of the pads of the PCB due to misalignment between the stencil and the PCB (the stencil apertures are designed to be the same size as the pad sizes of the PCB). The second is that part of the paste sticks to the sides of the stencil apertures. It was found that if the area ratio of BGA apertures equals that of QFP apertures, the two transfer ratios are also equal. That indicates that the relationship between transfer ratio and area ratio is independent of the aperture shape.

Fig. 7 gives the critical area ratio of 0.6 when the squeegee attack angle is $45^{\circ}$ and the seal condition between the squeegee and the stencil is very good. The maximum stencil thickness for a specified aperture size can be calculated based on the critical area ratio. In industry, different guidelines have been published. For example, Wilson and Bloomfield [6], [7] suggested an optimal aspect ratio of 1.25. Coleman [9] recommended larger than 1.5 for the aspect ratio and larger than.66 for the area ratio. Markstein [5] proposed the generally accepted rule that the aspect ratio be larger than 1.5 (1.8 for chemically-etched stencils and 1.2 for electropolished laser-cut and electroformed stencils). Here, the aspect ratio is defined as the width of the aperture divided by the height of the aperture (or the thickness of the stencil). It should be pointed out that the critical area ratio depends on the squeegee attack angle and the seal condition between the squeegee and the stencil according to our model.

Stencil thickness has its lower bound also. Analysis shows that the area of solder deposits increases slightly as the stencil thickness decreases. It indicates that too thin of a stencil could cause solder bridges. On the other hand, the decrease in stencil thickness results in the decrease of the aperture volume. The objective of solder deposition is to transfer a certain amount of solder paste to the PCB. Insufficient solder paste resulting from thinner stencil may cause solder opens. Therefore, a lower bound exists to achieve acceptable solder volume and area. In order to avoid solder bridges and solder opens, stencil thickness must be chosen larger than this lower bound.

The transfer ratio of the average experimental data in Fig. 7 is smaller than that of the theoretical model. This is because the points in Fig. 7 are the overall average of experimental data that have the same area ratio. The points in each column in Fig. 8 represent the average of the data that have the same area ratio in different experimental runs and different QFP aperture shapes. 


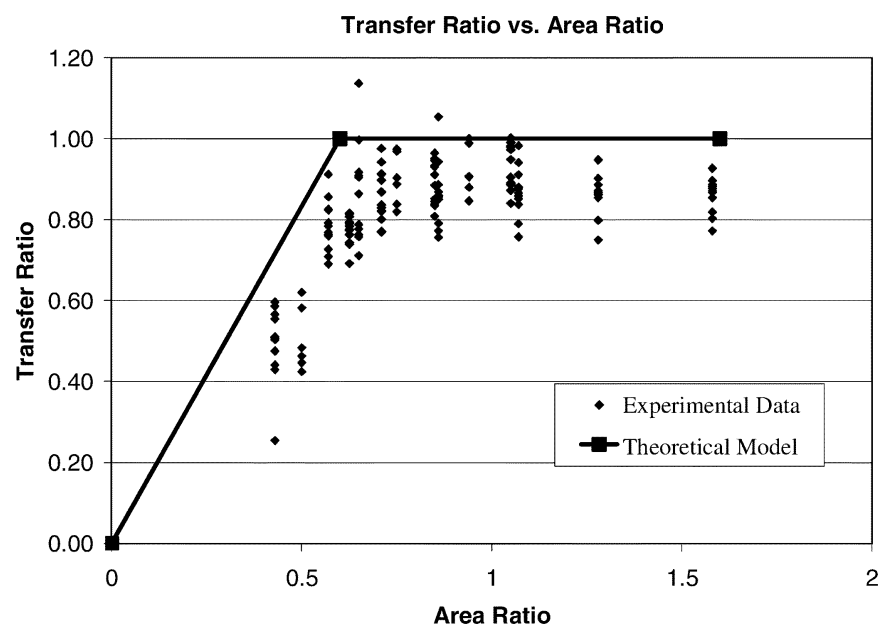

Fig. 8. Comparison of the model and experimental results (points: the average of experimental data that have the same area ratio in different experimental runs and different QFP aperture shapes; line: model).
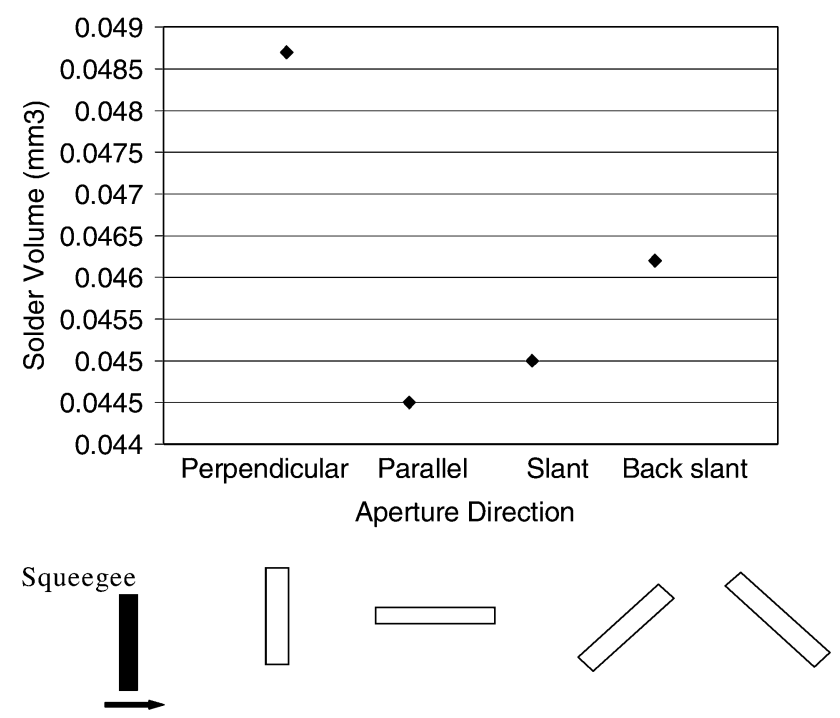

Fig. 9. Solder volume versus aperture orientation.

It was noted that there are two data points with transfer ratio slightly larger than 1.0. This may be due to the aperture size variations. Fig. 8 shows that some solder paste sticks to the aperture sidewall of the stencil when area ratio is less than 0.6. This is why all of the experimental points are less than the theoretical model predicts when the area ratio is less than 0.6. When the area ratio is greater than 0.6 , a smaller proportion of solder paste sticks to the sidewall.

\section{B. Effects of Aperture Orientation}

The plot of the mean of deposited solder volume versus aperture direction is shown in Fig. 9. It indicates that perpendicular apertures (longer side of the apertures perpendicular to the squeegee travel direction) deposit 8-9\% more volume than parallel apertures, while the volume difference between slant apertures and back slant apertures is much smaller. The actual aperture sizes of the two stencils were measured by a microscope since the information of aperture shape was confounded in this experiment. It was found that the perpendicular apertures were

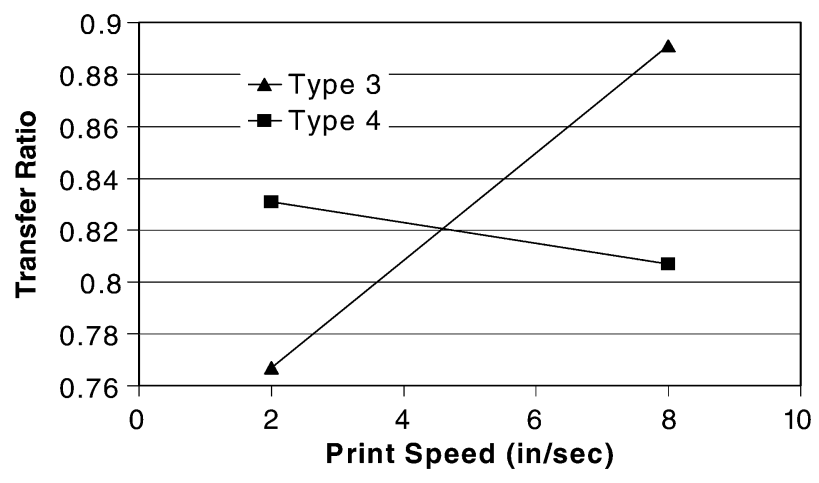

Fig. 10. Interaction plot of solder type and print speed for QFP apertures.

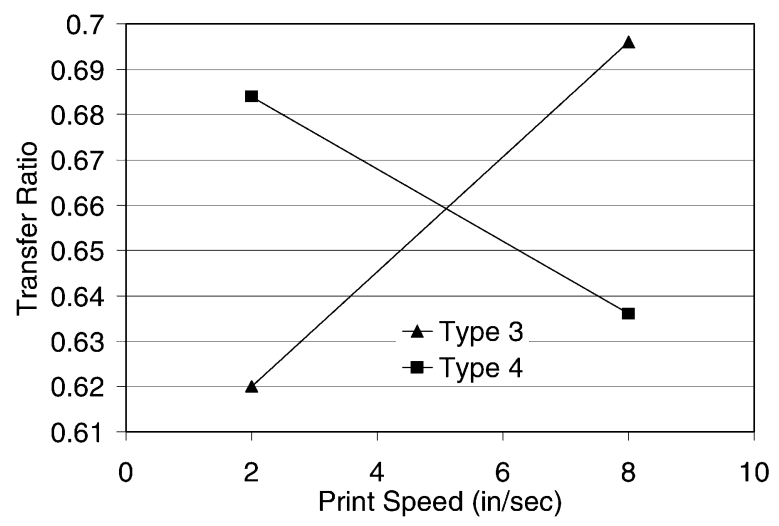

Fig. 11. Interaction plot of solder type and print speed for BGA apertures.

slightly (about 3\%) wider than the parallel apertures. There is no statistically significant difference between the slant aperture sizes and the back slant aperture sizes. Deducting the aperture size difference, perpendicular apertures print 5-6\% more volume than parallel apertures. Analysis on the height of solder deposits draws the same conclusion. This is a well known experimental phenomena [4], [5]. It can be concluded that arranging the squeegee $45^{\circ}$ with respect to the stencil apertures would decrease the variation of the solder deposits height and volume.

\section{Effects of Solder Paste and Print Speed}

The effect of print speed has confused many engineers because conflicting experimental results were reported. Mannan, et al. [4] found a linear rise in paste height with squeegee velocity during stencil printing. Wilson and Bloomfield [6], [7] reported that no noticeable deterioration in print height occurred in print speeds from $25 \mathrm{~mm} / \mathrm{s}$ to approaching $200 \mathrm{~mm} / \mathrm{s}$.

The ANOVA analysis in Tables V, VI, VIII, and IX shows that strong interaction between solder paste and print speed exists. The interaction plot of solder paste and print speed for QFP apertures and BGA apertures are shown in Figs. 10 and 11. It indicates that the transfer ratio of solder type three increases rapidly as the print speed increases while that of solder type four decreases a little bit as the print speed increases. It can be concluded that the selection of optimal print speed should be based on solder paste type and the print speed could be used to adjust the volume, area, and height of solder deposits.

From the ANOVA tables, it seems that solder paste does not have a significant effect on the amount of solder paste deposited. 


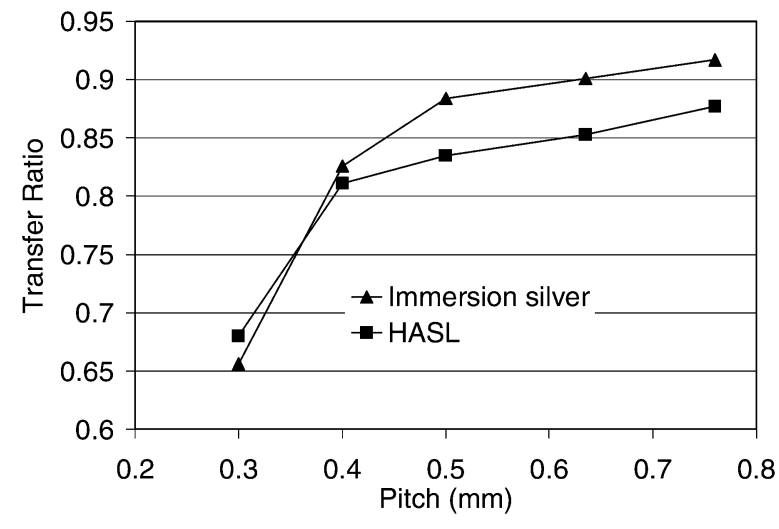

Fig. 12. Transfer ratio versus board finish for QFP apertures.

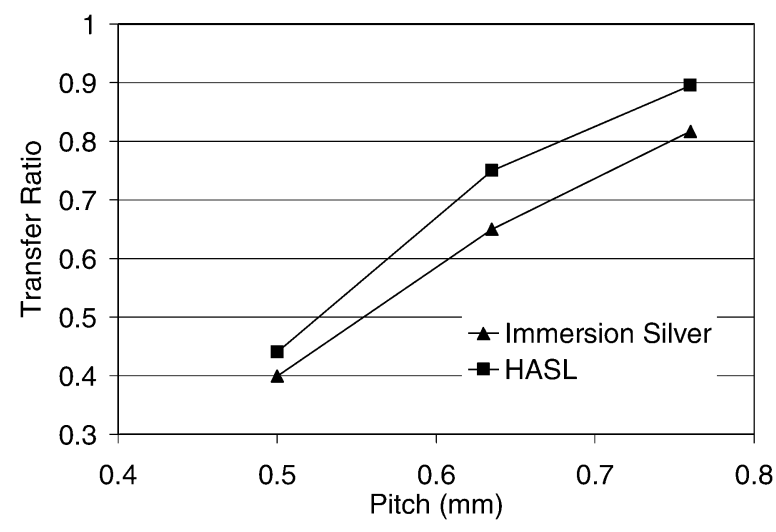

Fig. 13. Transfer ratio versus board finish for BGA apertures.

From the interaction plots in Figs. 10 and 11, it is difficult to draw the conclusion that solder paste does not have a significant effect because an interaction exists between solder type and print speed. Further investigation should be conducted by selecting three levels of print speed.

This experimental phenomena may be explained as follows: The amount of solder paste deposited is determined by the aperture opening size and paste pressure generated. The paste pressure is proportional to the viscosity of solder paste times the print speed [2]. Since solder paste is a non-Newtonian fluid, its viscosity changes with the change of shear rate. The high print speed results in a high shear rate so that the viscosity of the paste decreases. The result of the solder viscosity times the print speed depends on the solder rheology (the change in viscosity versus the shear rate). Different solder pastes have different rheologies. This is why an interaction exists between solder paste and print speed.

\section{Effects of Board Finish}

The most common surface finish of PCB is hot-air solder leveling (HASL). However, the dome of the pad (uneven surface) from HASL can affect the fine pitch solder paste printing [11]. Therefore, other surface finishes including immersion deposition are receiving attention these days. A comparison of different board finishes was made by Seto, et al. [12] and Bratin, et al. [13]. No reports on effects of board finish seem to have been published yet.
The relationship between the transfer ratio of deposited solder paste and the board finish for different pitches of QFP and for BGA are shown in Figs. 12 and 13. It indicates that more solder paste was deposited on HASL boards when the area of aperture opening is small (all BGA apertures and $0.3 \mathrm{~mm}$ pitch QFP apertures) while more solder paste was deposited on silver boards when the area of aperture opening is big (larger than $0.3 \mathrm{~mm}$ pitch QFP apertures). In addition, an interaction between solder type and board finish is found.

One of the important considerations of board finish is flatness of board surface. Generally, boards with immersion silver have a better surface in flatness than boards with HASL. The area of solder paste deposited on HASL boards is found always slightly larger than that on silver boards. This may be due to the dome shape of HASL board solder pads. The smooth surface with immersion silver allows the stencil to seal against the pad of the board and to prevent paste from forming solder bridging.

\section{CONCLUSION}

The following conclusions are drawn from our analysis.

1) The most critical process variables influencing the amount of solder paste deposited are aperture size and stencil thickness.

2) The transfer ratio is determined by the area ratio. Thicker stencils do not necessarily mean higher solder prints. The area ratio of larger than 0.6 is recommended for the selection of a proper stencil thickness.

3) An interaction between print speed and solder paste type was found, though solder paste itself does not have a significant effect on the amount of solder paste deposited. The interaction indicates that a proper print speed should be selected depending on the solder paste type. Further experiments with three or more levels of print speed are necessary to confirm the conclusion.

4) A perpendicular aperture prints higher and more volume than a parallel aperture. Aperture orientation of $45^{\circ}$ and $135^{\circ}$ with respect to the squeegee can decrease the variation of solder deposits.

5) Small apertures print more solder volume on HASL boards than that on immersion silver boards and big apertures print more solder volume on immersion silver boards than that on HASL boards.

\section{ACKNOWLEDGMENT}

The authors would like to thank Dr. I. Fidan and the technical reviewers for invaluable comments.

\section{REFERENCES}

[1] R. S. Clouthier, "The complete solder paste printing processes," Surf. Mount Technol., vol. 13, no. 1, pp. 6-8, 1999.

[2] J. Pan and G. L. Tonkay, "A study of the aperture filling process in solder paste stencil printing," in Electron. Manufact. Issues, Proc. ASME Int. Mech. Eng. Congr. Expo., Nashville, TN, 1999, pp. 75-82.

[3] J. Pan, G. L. Tonkay, R. H. Store, R. M. Sallade, and D. J. Leandri, "Gauge repeatability \& reproducibility study for a 3-D solder paste inspection system," in Proc. Int. Symp. Microelectron., Chicago, IL, 1999, pp. 532-537. 
[4] S. H. Mannan, N. N. Ekere, N. I. Ismail, and E. K. Lo, "Squeegee deformation study in the stencil printing of solder pastes," IEEE Trans. Comp., Hybrids, Manufact. Technol., vol. 17, pp. 470-476, Sept. 1994.

[5] H. W. Markstein, "Controlling the variables in stencil printing," Electron. Packag. Prod., vol. 37, no. 2, pp. 48-56, 1997.

[6] T. Wilson and D. Bloomfield, "An optimistic outlook for ultra fine pitch (part I)," Electron. Prod., pp. 39-42, Feb. 1995.

[7] — , "An optimistic outlook for ultra fine pitch (part II)," Electron. Prod., pp. 83-86, Mar. 1995.

[8] S. Fujiuchi and K. Toriyama, "Collective screen printing for carrier bump and SMT pads," in Proc. IEEE/CPMT Int. Electron. Manufact. Technol. Symp., 1994, pp. 109-112.

[9] W. E. Coleman, "Stencil design for advanced packages," Surf. Mount Technol., vol. 10, no. 6, pp. 34-37, 1996.

[10] J. Pan, "Modeling and Process Optimization of Solder Paste Stencil Printing for Micro-BGA and Fine Pitch Surface Mount Assembly," Ph.D. dissertation, Lehigh University, Bethlehem, PA, 2000.

[11] G. Trinite, "Importance of board planarity," Surf. Mount Technol., vol. 13, no. 1, pp. 12-13, 1999.

[12] P. Seto, J. Evans, and S. Bishop, "Analysis of the palladium finish," Surf. Mount Technol., vol. 13, no. 6, pp. 60-63, 1999.

[13] P. Bratin, M. Pavlov, and G. Chalyt, "Evaluating finishes using SERA," PC FAB, vol. 22, no. 5, pp. 30-37, 1999.

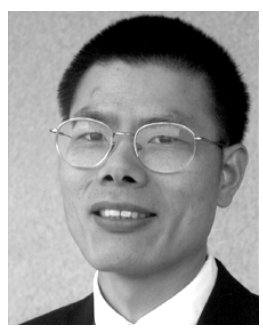

Jianbiao Pan (M'03) received the Ph.D. degree in industrial engineering from Lehigh University, Bethlehem, PA, in 2000.

$\mathrm{He}$ is an Assistant Professor in the Department of Industrial and Manufactuirng Engineering, California Polytechnic State University, San Luis Obispo. His current research interests are in electronics packaging, optoelectronics packaging, lead-free solder, statistical process control, and reliability.

Mr. Pan is a senior member of SME, and a member of IMAPS, and Sigma Xi.

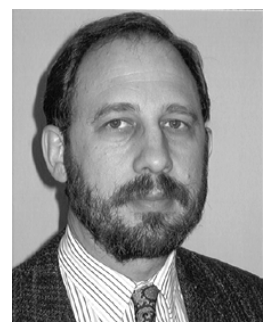

Gregory L. Tonkay received the B.S. (with highest distinction) and Ph.D. degrees in industrial engineering from Pennsylvania State University, University Park, in 1981 and 1987, respectively.

$\mathrm{He}$ is an Associate Professor and Associate Chair in the Department of Industrial and Systems Engineering, Lehigh University, Bethlehem, PA. He is the Director of the Electronics Manufacturing Laboratory and Associate Director of the George E. Kane Manufacturing Technology Laboratory, Lehigh, University. He has authored or coauthored over 25 technical papers. His areas of interest are manufacturing, automation, electronics manufacturing, and engineering education.
Robert H. Storer received the B.S. degree in industrial and operations engineering from the University of Michigan, Ann Arbor, in 1979, and the M.S. and $\mathrm{Ph} . \mathrm{D}$. degrees in industrial and systems engineering from the Georgia Institute of Technology, Atlanta, in 1982 and 1986, respectively.

$\mathrm{He}$ is a Professor of Industrial and Systems Engineering, and Co-Director of the Manufacturing Logistics Institute at Lehigh University, Bethlehem, PA. His interests lie in applied statistics and operations research.

Ronald M. Sallade received the B.S. degree (magna cum laude) in mechanical engineering and applied mechanics from the University of Pennsylvania, Philadelphia.

He is currently with Cygnus, Inc., Redwood City, CA, where he is involved in the development of medical device manufacturing for the biotechnology industry. Prior to that, he was with the Advanced Manufacturing Technology Division of the Visteon enterprise of Ford Motor Company, Lansdale, PA. He has made extensive improvements in manufacturing for the electronics industry in the areas of screen printing and machine vision.

Mr Sallade received the Ford's President's Award in 1999 for Customer Driven Quality as a member of the Worldwide Screen Printing Process Improvement Team for his developments in the screen printing arena.

Dave J. Leandri received the B.S. degree in ceramic engineering from Pennsylvania State University, University Park, in 1987, the M.S. degree in engineering science from Pennsylvania State University, Great Valley, in 1995, and the M.S. degree in technical management from the Wharton School of Business, University of Pennsylvania, Philadelphia, in 2002.

He is currently a Quality Manager with American Technical Ceramics, Jacksonville FL. Prior to that, he was an Advanced Manufacturing Engineer and Supplier Quality Manager for Visteon Automotive Systems, Lansdale, PA, from 1991 to 2000

Mr Leandri was awarded the Ford President's Customer Driven Quality Award in 1999 as the Team Leader for the Ford Worldwide Screen Printing Process Improvement Team. He holds three U.S. patents and one European Patent. 